\title{
MEDICINE AND THE LAW
}

\section{Guidelines for the use of WhatsApp groups in clinical settings in South Africa}

\author{
C Bouter, ${ }^{1}$ BHSc; B Venter, ${ }^{2}$ LLB, LLM; H Etheredge, ${ }^{1,3} \mathrm{PhD}$ \\ ${ }^{1}$ Wits Donald Gordon Medical Centre, Faculty of Health Sciences, University of the Witwatersrand, Johannesburg, South Africa \\ ${ }^{2} \mathrm{PhD}$ candidate, Centre for Health, Law and Society, University of Bristol Law School, University of Bristol, UK \\ ${ }^{3}$ Department of Internal Medicine, Faculty of Health Sciences, University of the Witwatersrand, Johannesburg, South Africa
}

Corresponding author: H Etheredge (harriet.etheredge@mediclinic.co.za)

\begin{abstract}
In everyday clinical practice, healthcare professionals (HCPs) are exposed to large quantities of confidential patient information, and many use WhatsApp groups to share this information. WhatsApp groups provide efficient mechanisms for clinical management advice, decisionmaking support and peer review. However, most HCPs do not fully understand the legal and ethical implications of sharing content in a WhatsApp group setting, which is often thought to be hosted on a secure platform and therefore removed from public scrutiny. In our paper, we unpack the legal and ethical issues that arise when information is shared in WhatsApp groups. We demonstrate that sharing content in this forum is tantamount to the publication of content; in other words, those who share content are subject to the same legal ramifications as a journalist would be. We also examine the role of the WhatsApp group administrator, who bears an additional legal burden by default, often unknowingly so. We consider the recommendations made by the Health Professions Council of South Africa in their guidelines for the use of social media, and highlight some areas where we feel the guidelines may not adequately protect HCPs from the legal repercussions of sharing content in a WhatsApp group. Finally, we provide a set of guidelines for WhatsApp group users that should be regularly posted onto the group by the relevant group administrator to mitigate some of the legal liabilities that may arise. We also provide guidelines for group administrators.
\end{abstract}

S Afr Med J 2020;110(5):364-368. https://doi.org/10.7196/SAMJ.2020.v110i5.14558

Healthcare professionals (HCPs) are exposed to large quantities of confidential patient information daily. In parallel, the changing nature of patient management with a focus towards multidisciplinary care requires sharing of this confidential information with ever-larger numbers of colleagues. This is often done through WhatsApp groups, which are distinct from one-on-one WhatsApp conversations as they involve $\geq 2$, but often a very large number of people. All these individuals may read content posted onto the group and may respond to it. There is no doubt that sharing-services such as WhatsApp have huge advantages in healthcare. For instance, members of multidisciplinary teams on a WhatsApp group can access the opinion of their peers at almost any given time without the logistical challenge of having to meet in person. ${ }^{[1-4]}$ The benefit of quick, easy information sharing extends to rural and semi-urban health contexts, where WhatsApp groups facilitate remote consultations with specialists. This has proven valuable, especially in a resource-limited country such as South Africa (SA), where HCPs in outlying areas can use the groups to access specialist medical opinion in complex cases, e.g. patients with HIV and antiretroviral resistance. ${ }^{[5,6]}$ Due to its usefulness and cost effectiveness, WhatsApp is also being tested as a learning tool for doctors and medical students. ${ }^{[7,8]}$

In spite of its widespread use, understanding and acknowledgement of the legal framework underpinning the group-sharing of confidential patient information are sorely lacking among HCPs. ${ }^{[7,9]}$ Indeed, it is possible to forget that WhatsApp is a form of social media and to let one's guard down, e.g. by starting a personal interaction in a group setting that all group members can view. The primary consideration that HCPs seem to overlook when sharing information in a WhatsApp group is that once the information has been seen by one other person, it is considered 'published'. ${ }^{[10]}$ This amounts to the same as having published it as a newspaper headline, and the shared content is subject to the same legal scrutiny and rules as those for a journalist writing content in a newspaper. In our thorough review of the healthcare literature related to social media in SA, we could not find an article that suitably emphasised this fact in relation to WhatsApp or any other social media platform and explored the myriad of legal implications it entails. ${ }^{[9,11]}$

Our article explores the use of WhatsApp groups in medicine in SA and explains the legal pitfalls that all HCPs using WhatsApp groups should be aware of. We discuss the limitations of the Health Professions Council of South Africa (HPCSA)'s 'Ethical guidelines on social media ${ }^{\text {[12] }}$ and offer some guidelines for the administration and use of WhatsApp groups in healthcare (Box 1). We hope these will facilitate legally and ethically sound use of this powerful informationsharing platform in the best interests of HCPs and patients.

\section{Ethics and the use of WhatsApp groups}

Worldwide, academic articles specifically outline the advantages and disadvantages of using WhatsApp in the clinical setting and discuss the ethical issues. ${ }^{[7]}$ Common themes are lack of consideration for patient confidentiality, privacy and consent, and there are several suggestions from authors on how to increase information and communication technology governance. ${ }^{[2,13]}$ Some healthcare systems, such as the National Health Service (NHS) in the UK, have provided guidelines on the use of instant messaging platforms in the acute clinical setting. However, they strongly advise against using these platforms to conduct clinical communications due to the 


\section{Box 1. Guidelines for healthcare practitioners and group administrators using WhatsApp groups}

\section{Guidelines for healthcare practitioners}

- Please note that the aim of this group is to provide an objective forum for medical discussion. It is not a social group and members are asked to refrain from sharing information that is not relevant.

- In terms of the legislation, it is presumed that when a practitioner posts patient information on the group, the consent of said patient to post this information has been given in writing, according to the Health Professions Council of South Africa (HPCSA)'s guidelines.

- Please respect the privacy of other group members and do not discuss the content of the WhatsApp group with anyone outside the group.

- Please do not share posts or screenshots from the group on other social media platforms.

- Remember that we cannot guarantee the confidentiality of anything you post on this group or your identity, so please post with care.

- If you want to leave the group, you can do so at any time and you do not need to give a reason.

- Anyone posting content that is deemed inappropriate, will be removed from the group. The facilitator's decision in this regard is final.

- If you deem content on the group to be defamatory or inappropriate, please explicitly disassociate yourself from the content by commenting on its inappropriateness, or by leaving the group.

- Any post that is not considered relevant to the scope of the group - for instance advertising posts - will be flagged as inappropriate by the facilitator, at the discretion of the facilitator.

- If you have an issue with the conduct of other group members, please raise this with the facilitator in a separate WhatsApp chat.

- Ensure that pictures shared on the group are not automatically saved on your camera roll. You can ensure this by changing the settings in the group info tab.

\section{Guidelines for group administrators}

- Note that according to publication legislation in South Africa, once a WhatsApp message has been seen by $>2$ people, it is officially considered 'published'. Hence, it is very important to ensure that the content of the group remains appropriate to the topic.

- If someone posts something that you deem inappropriate, it is important to immediately dissociate yourself from that comment. As the facilitator, this is vital because you will ultimately be responsible for monitoring the conduct of the other group members.

- Where possible, identify another person on the group who can co-administer with you.

- Always inform new members of the purpose and rules of engagement of the group (you can do this by posting the abovementioned guidelines).

- Ensure that all group members explicitly agree to adhere to the rules of the group (those posted above) and keep a record of this agreement to mitigate your own legal liability.

- Establish a clear, fair process that should be followed when there is a complaint about inappropriate content on the group. This should detail who to complain to, what content is required and the timeframe for complaints.

- Act immediately if a complaint arises.

- Knowing all members of a group personally before you authorise their participation is an added advantage, although it is not always practical in the healthcare context.

inherent risk of storing patient information on personal devices and servers that have no special precautions required by informationprotection legislation such as the General Data Protection Regulation 2016/679 (GDPR). ${ }^{[14]}$

Due to the numerous advantages, the HPCSA social media guidelines acknowledge that social media now forms an integral part of clinical practice, and from this we can broadly infer that use of social media within these guidelines is ethical. Moreover, the few publications considering ethical implications of social media in clinical settings in SA further entrench this notion, provided social media use respects the limits of confidentiality, the requirement for consent and does not bring the health profession into disrepute. ${ }^{[9,11]}$

\section{Legislative framework for WhatsApp groups}

There is no clear legislative framework regulating WhatsApp groups in SA; hence, common law and the SA Constitution ${ }^{[15]}$ are the legal foundation, and additional statutes could apply (Box 2). Legal uncertainty is further exacerbated because SA courts have had limited exposure to cases based on social media. However, past cases suggest that the courts will not tolerate online defamation. The Cybercrimes and Cybersecurity Bill (still to become law) ${ }^{[25]}$ could assist in providing more clarity. This Bill stipulates that a person could be committing a criminal offence if they distribute or broadcast a message that is harmful to another person. Unfortunately, none of the above provides unequivocal legal guidance on the use of WhatsApp groups.

\section{The law and ethics in practice}

So what is the upshot of this legislation and the available ethical guidance? It appears that WhatsApp group use is ethically acceptable provided it does not infringe the rights of others. Legally, the situation seems much more complex. In SA, content is considered published once it has been seen (or heard in the case of a video) by one other person. ${ }^{[10,26]}$ This definition of publication stems from collective interpretation of legislation and common law. It means that when an individual posts to a WhatsApp group, it is equivalent to posting the message, along with the details of the originator, on a billboard for all to see. ${ }^{[10]}$

However, the situation in a WhatsApp group is further complicated because by virtue of being in the group, all members can become part of the chain of publication. ${ }^{[10]}$ This is generally taken for granted, and it is not something people consider seriously. We can become part of the chain of publication and be considered legally liable for content on this basis if we share content, like it, comment on it or allow its dissemination to continue in the event that we had the power to stop it. We are then considered as responsible for the content as the person who originally generated and posted it. Moreover, if the content posted on the WhatsApp group devolves to become inappropriate, illegal or unethical, individuals in the group would be in the chain of publication if they failed to actively and overtly dissociate themselves from the content, for instance by leaving the group or commenting on the inappropriate post to express their view that it is inappropriate. ${ }^{[10]}$

We may think that if we simply view content, we are safe, because we have not engaged with it. However, the precedent in SA case law is 
that if we view offensive content, yet we do not engage with it in any way - for instance, we do not share it, like it or comment on it - it is still considered as our tacit acceptance of the content as appropriate (Box 3). ${ }^{[27]}$ We have failed to openly state that we find the content inappropriate or harmful.

\section{The WhatsApp group administrator}

Additionally, the administrator of a WhatsApp Group can be considered responsible for all content posted - even if it originated from other people. ${ }^{[10]}$ Many people do not realise that they become WhatsApp group administrators by default when they start a group. As the administrator, you can appoint others to co-administer the group, but you cannot remove yourself from the administrative position unless you leave the group. If you do so, WhatsApp automatically appoints someone else on the group as the administrator - and this person is not sent any notification of their change in status. They are also not made aware of the accompanying legal responsibility.

\section{Box 2. Additional legislation applicable to WhatsApp group chats}

- Films and Publications Amendment Act No. 11 of 2019[16]

- Protection of Personal Information Act No. 4 of $2013^{[17]}$

- Employment Equity Act No. 4 of $2013^{[18]}$

- Protection from Harassment Act No. 17 of 2011 $1^{[19]}$

- Regulation of Interception of Communications and Provisions of Communication-related Information Act No. 70 of $2002^{[20]}$

- Electronic Communications and Transactions Act No. 25 of $2002^{[21]}$

- Promotion of Equality and Prevention of Unfair Discrimination Act No. 4 of $2000^{[22]}$

- Labour Relations Act No. 66 of $1995^{[23]}$

- Trademarks Act No. 194 of $1993^{[24]}$

\section{Box 3. Isparta v Richter and Another ${ }^{[27]}$}

This case was heard in the High Court of South Africa in September 2013.

Isparta was previously married to the second defendant. They had divorced, and at the time of the case Richter was married to the second defendant. Isparta had gone on to remarry another man, who had a 16-year-old son. She also cared for her 2 children, aged 6 and 4 years, from her marriage to the second defendant. Richter took to Facebook and posted defamatory content about Isparta in two instances. Richter tagged both her husband (the second defendant) in the posts, and Isparta. In the first post, Richter notes that Isparta had an unhealthy interest in her (Richter's) private life, and she ridiculed Richter for this, as well as naming Isparta's children in the post. In the second post, Richter suggests that Isparta was promoting a type of paedophilia by allowing the 16-year-old son into the bathroom while the younger children were bathing. The defendants stated that they believed Facebook was a public platform designed for everyone to share their views, and as such they did not consider their actions deplorable.

Of relevance to this article, is that the husband (the second defendant) did not respond to the Facebook postings in any way. He did not like them, he did not comment on them and he did not share them. Furthermore, he did not delete the posts in question.

The court found Richter guilty of defamation and ordered damages of ZAR40 000 against her. Her husband, the second defendant, was found to be equally liable because he did not actively dissociate himself from the posts, which was seen as his tacit acceptance of and agreement with their content.
The administrator of a WhatsApp group is regarded much like an editor, in that the former provides the platform for discussions and sharing of information and is responsible for the content. In a WhatsApp group setting this is particularly complex because the administrator does not have prior knowledge of what will be published until it has been shared in the group. At this point, the administrator would need to act decisively to disassociate the group with the post to avoid legal implications - this might be by commenting on the inappropriateness of the post, deleting the post or removing the offending member from the group.

WhatsApp group administrators should be aware that the courts and opposing legal counsel could subpoena them for the full transcript of a WhatsApp discussion. The legal basis for this is provided in WhatsApp's privacy policy document, which states that 'we collect, use, preserve and share your information if we have goodfaith belief that it is reasonably necessary to: (a) respond pursuant to applicable law or regulations, to legal process or to government requests ..... ${ }^{[28]}$ Secondly, in terms of the Electronic Communications and Transactions Act, section 15 creates a rebuttable presumption that data messages and/or printouts thereof are admissible in evidence, provided they comply with the requirements governing the admissibility of documentary evidence. ${ }^{[21]}$ Thirdly, in a 2019 landmark ruling by the Kimberley Magistrate's Court, an owner of a security company was ordered to make the chats contained in a WhatsApp group available to the court as evidence in a harassment protection order case. ${ }^{[29]}$ The magistrate referred to the fact that social media cases highlight the shortcomings of SA legislature and the importance of the Constitution.

In some cases, a WhatsApp group administrator may wish to make a defence of innocent dissemination when inappropriate content is posted on the group. ${ }^{[30]}$ The innocent dissemination defence can be made when a person has unwittingly shared content without negligence on their part. However, the law is unclear on how little knowledge of the content a WhatsApp group administrator would need to have to make this defence and escape liability for such content. Either way, individuals should not rely on the innocent dissemination defence, as its limits have not been legally defined.

\section{Implications in the healthcare setting}

Healthcare-related WhatsApp groups sharing patient information are complex, and the legal classification of the content of the WhatsApp group chat adds further ambiguity to this discussion. In all likelihood, the content will be broadly classified as medical records.

Because medical records and patient information are supposed to be held in confidence, sharing is only considered ethical and legally justifiable when divulged to the medical team immediately responsible for treating the patient, when sharing the information is in the public interest, and provided the patient has consented to such sharing. According to the HPCSA social media guidelines, this consent should be procured in writing. If in doubt about whether consent has been obtained or not, the HPCSA social media guidelines advise that one refrains from posting the associated information. ${ }^{[12]}$ Sharing information on especially large WhatsApp groups for the purposes of training, would therefore not be considered ethical, unless the patient has consented. Similarly, seeking the opinion of outside experts who are not involved in the medical care of the patient, would also require written authorisation from the patient. Furthermore, the written consent of a parent or guardian must be obtained when dealing with a minor $<12$ years of age. ${ }^{[31]}$ It is advisable that an administrator does not rely on broad consent from the patient in this regard. If possible, the patient should be informed explicitly of how their information will be disclosed and of the purpose of the disclosure. 
Sadly, in our experience, it is also the case that healthcare-related WhatsApp groups can devolve into conversations of a more personal nature, which are not related to patient care. These conversations can include HCPs making inappropriate comments about patients, each other or their institutions. Therefore, when there are posts that involve defamatory comments about individuals on the group, or those who are not part of the group, participants must consider both the legal and professional ramifications and very carefully weigh up whether remaining part of a WhatsApp group where this type of content is regularly posted is worthwhile.

The HPCSA social media guidelines acknowledge that reputation management in healthcare is paramount, and that individual practitioners should not comment about the probity or competence of other practitioners on social media, as this may damage public trust in healthcare providers. What they do not stress enough is that, should a statement be defamatory, it could result in legal action against the individual and the organisation they are representing, and that vicarious liability could apply in these cases. The HPCSA social media guidelines ${ }^{[12]}$ further state that, should an HCP see inappropriate comments made by another HCP on social media, these should be brought to their attention discreetly. Given the law around this issue, we do not agree with this recommendation. To avoid falling foul of publication legislation in SA, an active and overt dissociation with inappropriate content is recommended, not a quiet pep-talk.

\section{Legall protections for patients and healthcare professionals}

The SA law of delict plays a significant role in offering legal protections for patients, as it provides the aggrieved party with a means to claim damages. If a situation occurs where a patient's right to confidentiality has been breached on a WhatsApp group, the patient could rely on the following remedies: $(i)$ institute a civil action against the wrongdoer for breach of privacy or defamation; (ii) if an HCP is the wrongdoer, a complaint can be laid with the relevant professional council; or (iii) a complaint can be laid with the employer of the wrongdoer for disciplinary action to be taken..$^{[32]}$

The rights afforded to people wronged during the course of a WhatsApp group chat begs the question about the protections that are available to HCPs who may be implicated in legal proceedings or complaints. While the HPCSA social media guidelines outline some precautionary measures, they do not state what HCPs in this situation should do. Hence, the extent to which practitioners would be defended by the HPCSA is unclear. Moreover, we could not find any documentation outlining the position of local or provincial government regarding protections afforded to government employees in a social media context. This should be remedied, as the state sector is a major employer of HCPs in SA.

The largest medical insurer in SA, the Medical Protection Society (MPS), has issued guidelines for responsible social media use among its members. The guidelines do not state the extent to which the MPS will indemnify members in the event of social media-related claims. However, Dr Graham Howarth, CEO of the MPS, stated the following (personal communication, 11 February 2020): 'We are not an insurance company but a mutual [fund] and our customers are members and they have the right to request assistance. If they were in the correct membership at the time of the incident we then exercise discretion regarding assistance. It would be most unusual for us not to assist in an instance where there has been an alleged breach of confidentiality.' However, he goes on to express uncertainty about the position of the MPS in assisting members where allegations against them are related more to their administrative function, e.g. where the HCP was not directly involved in the patient's care and was not directly responsible for the breach of confidentiality. This highlights the ambiguity surrounding responsible use of WhatsApp groups and the implications of the large and interconnected networks it creates.

\section{Liability of the WhatsApp group administrator in the healthcare context}

So what happens if the content of a WhatsApp group devolves, the administrator is a health professional and a legal challenge is brought by the aggrieved party in terms of the law of delict? In these cases, the salient features of the obligation ex delicto will include a strong commitment to long-standing principles of medical ethics such as confidentiality. Furthermore, in terms of the maxim imperitia culpae adnumeratur, an HCP is expected to act with a reasonable degree of skill and expertise, which goes beyond that expected of the general public. Hence, if an HCP is the administrator of a WhatsApp group that shares patient information unethically or illegally, they would be tested against a higher threshold than a reasonable person (non-HCP).

\section{Guidelines for healthcare professionals using WhatsApp groups and administrators of such groups}

To protect both the administrators and users of WhatsApp groups, we have developed two guidelines. The first set, for members of WhatsApp groups, should be regularly posted on any group chat by the administrator so that no-one can say they have not seen them. The second set is for WhatsApp group administrators. The guidelines are set out in Box 1 and can be adapted to meet the needs and scope of a specific group.

\section{Conclusions}

Social media use in healthcare is here to stay, and there is little doubt that when used responsibly, and with patients' consent, social media can be harnessed in the best interests of patients. However, members of WhatsApp groups and the administrators of these groups need to balance the accruing benefit to patients with the potential harms of becoming party to an inappropriate and legally incriminating chain of publication. It is also vital to remember that such publication is instantaneous, and it may only take a few seconds for inappropriate content to be seen - or shared - by others, even if it has been deleted by the originator. As sharing content can be as simple as taking a screenshot, it is always essential that HCPs think carefully about their content before posting it.

Our appraisal of the relevant publication legislation demonstrates that WhatsApp groups may have more pitfalls than immediately meet the eye. Unlike other SA articles in this field, we have specifically considered the role of publication in the WhatsApp group context. We feel that this is extremely important information for HCPs who might use WhatsApp groups to share information, and it has been overlooked. There are numerous ethical and legal ramifications in a context that effectively amounts to the publication of confidential information - even if this is done unwittingly - and HCPs need to be aware of these in their entirety.

Declaration. None.

Acknowledgements. None. 
Author contributions. All authors contributed equally to the manuscript. The authorship team is multidisciplinary in expertise and all authors contributed to their areas of specialty, as well as drafting and approving the final version of the manuscript.

Funding. None.

Conflicts of interest. None.

1. Crisan-Dabija RA, Mihaescu T. Creating a successful medical team using Whatsapp(TM). Eur Respir J 2018;52(Suppl 62):A4115. https://doi.org/10.1183/13993003.congress-2018.PA4115

2. Kamel Boulos M, Giustini D, Wheeler S. Instagram and WhatsApp in health and healthcare: An overview. Future Internet 2016;8(3):37. https://doi.org/10.3390/fi8030037

3. O'Neill KM, Holmer H, Greenberg SLM, Meara JG. Applying surgical apps: Smartphone and tablet apps prove useful in clinical practice. Bull Am Coll Surg 2013;98(11):10-18.

O'Sullivan DM, O'Sullivan E, O'Connor M, Lyons D, McManus J. WhatsApp Doc? BMJ Innov 2017;3(4):238. https://doi.org/10.1136/bmjinnov-2017-000239

5. Venter W, Coleman J, Chan VL, et al. Improving linkage to HIV care through mobile phone apps: Randomized controlled trial. JMIR mHealth uHealth 2018;6(7):e155. https://doi.org/10.2196/ mhealth. 837

6. Venter WD, Fischer A, Lalla-Edward ST, et al. Improving linkage to and retention in care in newly diagnosed HIV-positive patients using smartphones in South Africa: Randomized controlled trial. JMIR mHealth uHealth 2019;7(4):e12652. https://doi.org/10.2196/12652

7. Woods J, Moorhouse M, Knight L. A descriptive analysis of the role of a WhatsApp clinical discussion group as a forum for continuing medical education in the management of complicated HIV and TB clinical cases in a group of doctors in the Eastern Cape, South Africa. South Afr J HIV Med 2019;20(1):9. https://doi.org/10.4102/sajhivmed.v20i1.982

8. Institute of Healthcare Management. Whatsapp doc: Legal and practical perspectives of using mobile Institute of Healthcare Management. Whatsapp doc: Legal and practical perspectives of using mobile
messaging. 2018. https://ihm.org.uk/whatsapp-doc-legal-and-practical-perspectives-of-using-mobilemessaging. 2018. https://ihm.org.uk/whats
messaging/ (accessed 12 December 2019).

9. Opperman CJ, van Vuuren MJ. WhatsApp in a clinical setting: The good, the bad and the law. S Afr J Bioethics Law 2018;11(2):102-103. https://doi.org/10.7196/SAJBL.2018.v11i2.00643

10. Sadlier E, Harrison L. Selfies, Sexts and Smartphones: A Teenager's Online Survival Guide. Cape Town: Penguin, 2019.
11. Grobler C, Dhai A. Social media in the healthcare context: Ethical challenges and recommendations. S Afr J Bioethics Law 2016;9(1):22-25. https://doi.org/10.7196/SAJBL.2016.v9i1.464

. Health Professions Council of South Africa. Ethical guidelines on social media. 2019. https://www. hpcsa.co.za/Uploads/Events/Conference/20Aug_Session_4_Guidelines_for_Social_Media.pd
(accessed 12 December 2019). (accessed 12 December 2019)

3. Mars M, Scott SE. WhatsApp in clinical practice: A literature review. Stud Health Technol Inform 2016;231:82-90.

4. European Parliament and Council of the European Union. General data protection regulation, OJL 119, 04.05. 2016. https://gdpr-info.eu/ (accessed 12 December 2019).

15. South Africa. Bill of Rights of the Constitution of the Republic of South Africa. 2005.

16. South Africa. Films and Publications Amendment Act No. 11 of 2019.

17. South Africa. Protection of Personal Information Act No. 4 of 2013.

18. South Africa. Employment Equity Act No. 4 of 2013

19. South Africa. Protection from Harassment Act No. 17 of 2011.

20. South Africa. Regulation of Interception of Communications and Provisions of Communicationrelated Information Act 70 of 2002 .

21. South Africa. Electronic Communications and Transactions Act No. 25 of 2002.

22. South Africa. Promotion of Equality and Prevention of Unfair Discrimination Act No. 4 of 2000.

22. South Africa. Labour Relations Act No. 66 of 1995.

23. South Africa. Labour Relations Act No. 66 of 1995.
24. South Africa. Trade Marks [sic] Act No. 194 of 1993.

24. South Africa. Trade Marks [sic] Act No. 194 of 1993.

25. South Africa. Cybercrimes and Cybersecurity Bill, No. B6, 2017. Nel S. Online defamation: The problem of unmasking anonymous online critics. Compar Int Law South Afr 2007;40(2):93-214,

27. Isparta v Richter and Another 2013 (6) SA 529 (G)

28. WhatsApp Terms of Service. https://www.whatsapp.com/legal/\#terms-of-service (accessed $12 \mathrm{Feb}-$ ruary 2020).

29. Juta and Company (Pty) Ltd. Magistrate orders WhatsApp messages to be made available. S Afr Lawyer, 24 May 2019.

30. Law Council of Australia. Review of model defamation provisions. 2019. https://www.justice.nsw. gov.au/justicepolicy/Documents/review-model-defamation-provisions/Final-CAG-DefamationDiscussion-Paper-Feb-2019.pdf (accessed 12 December 2019)

31. South Africa. National Health Act No. 61 of 2003.

32. Neethling J, Potgieter J, Knobel JC. Law of Delict. 7th ed. Cape Town: Lexis Nexis, 2016.

Accepted 26 February 2020 